Revista Destaques Acadêmicos, Lajeado, v. 11, n. 1, 2019. ISSN 2176-3070

DOI: http://dx.doi.org/10.22410/issn.2176-3070.v11i1a2019.2061

http://www.univates.br/revistas

\title{
AVALIAÇÃO DO DESENVOLVIMENTO DA METODOLOGIA DE APRENDIZAGEM BASEADA EM PROBLEMAS NA DISCIPLINA DE CONTABILIDADE NO CURSO DE TÉCNICO EM ADMINISTRAÇÃO
}

\author{
André Luis Eifler ${ }^{1}$, Edson Moacir Ahlert ${ }^{2}$
}

\begin{abstract}
Resumo: O professor precisa ser criativo e flexível em escolher procedimentos visando integrar o conteúdo, a disponibilidade do tempo e as particularidades de cada assunto, possibilitando um melhor desenvolvimento da capacidade cognitiva dos alunos. A presente pesquisa, de cunho descritiva e abordagem quanti-qualitativa, embasada em pesquisa bibliográfica e levantamento de dados, objetivou destacar a utilização da Aprendizagem Baseada em Problemas, nas aulas da disciplina de Contabilidade, no curso Técnico em Administração, do Centro de Educação Profissional da Universidade do Vale do Taquari - Univates. Buscou-se também descrever o desenvolvimento da metodologia ativa utilizada com o grupo de alunos num intervalo de três aulas, bem como investigar as percepções quanto à eficiência do método, por meio de um questionário. Os dados sugerem que os alunos perceberam que aprendem melhor, quando participam de forma ativa e desafiadora, em condições de aplicar o aprendizado experimentado em sala de aula em situação que se apresentam nas empresas onde atuarão. Os respondentes afirmam, em sua maioria, que percebem a estratégia de ensino utilizada como aspecto favorável ao bom funcionamento da dinâmica em sala de aula, e êxito no relacionamento entre professor e alunos.
\end{abstract}

Palavras-chave: Metodologias ativas. Aprendizagem Baseada em Problemas. ABP.

\section{INTRODUÇÃO}

As Instituições de Ensino Técnico e Profissional são responsáveis pela formação de profissionais qualificados, para atuarem nas mais diversas áreas. Nesse sentido, deve existir uma constante busca da melhoria do processo de ensino e aprendizagem, para garantir a qualidade da educação profissional.

1 Graduado/Bacharel em 2002 no Curso de Ciências Contábeis. Acadêmico do Curso de PósGraduação Lato Sensu - Especialização em Docência na Educação Profissional da UNIVATES.

2 Professor da UNIVATES. Mestre em Ambiente e Desenvolvimento. 
Gil (2015, p. 79) destaca que "requer-se, portanto, competência do professor para proceder ao diagnóstico das necessidades e das expectativas dos estudantes com vistas a prescrever as medidas educativas mais adequadas". Assim, cabe ao professor o discernimento de avaliar os passos didáticos com bom senso e clareza, incentivando a proatividade dos alunos no sentido que eles participem efetivamente das aulas, buscando a solução de problemas por meio da curiosidade, e do apoio em leituras, pesquisas, bem como desenvolvendo a habilidade de perguntar em detrimento da mera decoreba de respostas.

Para Moran (2013), a escola padronizada exige resultados previsíveis enquanto que a sociedade do conhecimento se baseia em competências cognitivas, pessoais e sociais exigindo proatividade, colaboração e visão empreendedora. Assim, as instituições de ensino precisam promover a produção e desenvolver novos conhecimentos e metodologias ativas para melhorar o processo de ensino e aprendizagem.

Segundo Berbel (2011), as metodologias ativas têm o objetivo de potencializar a curiosidade, em que os alunos se inserindo os alunos na teoria e trazendo elementos novos, ainda não considerados nas aulas ou na própria perspectiva do professor.

Para Moran (2013), a priori, para que os alunos sejam proativos, haverá uma necessidade de adotar metodologias em que eles se envolvam em atividades cada vez mais complexas, em que tenham que tomar decisões e avaliar os resultados, com apoio de materiais relevantes.

Com a utilização de metodologias ativas, o papel do professor passa a ser de facilitador no processo de aquisição do conhecimento, e para isso, precisa organizar o processo, tornando o ambiente mais dinâmico e incentivando a cooperação entre pares no ambiente de sala de aula.

O objetivo deste trabalho é verificar, na percepção do docente e na avaliação dos alunos, possíveis reflexos da aprendizagem baseada em problemas, conhecida pela sigla $\mathrm{ABP}$, na disciplina de Contabilidade, no curso Técnico em Administração, do Centro de Educação Profissional da Universidade do Vale do Taquari - Univates, com enfoque em fluxo de caixa.

Conforme Anastasiou e Alves (2004), a estratégia de resolução de problemas abrange a construção do conhecimento por meio da estimulação ou ampliação dos significados aprendidos com relação à realidade ou área profissional. Há uma constante nessa construção do conhecimento, desde o levantamento e análise dos dados, até as diversas alternativas de solução.

No intuito de atingir o objetivo geral, estipulamos os seguintes objetivos específicos: i) utilizar a Aprendizagem Baseada em Problemas nas aulas sobre um assunto específico: fluxo de caixa; ii) descrever a forma de desenvolvimento da metodologia ativa empregada; iii) investigar as percepções dos alunos quanto à $\mathrm{ABP}$. 
O presente trabalho pode trazer contribuições aos professores que atuam nas disciplinas de Ciências Contábeis, que em sua grande maioria, são profissionais liberais, sem dedicação à docência e, geralmente, não possuem formação pedagógica. Além disso, trabalhos dessa natureza ajudam a geração de novos conhecimentos.

O desafio é proporcionar ao aluno a migração de uma aula expositiva, centrada no professor e seus conteúdos, para uma forma mais aberta, com perspectivas de tirá-lo da zona de conforto, assim o professor deixa de ser o protagonista na sala de aula e o aluno deixa de ser mero receptor passivo da informação.

\section{APRENDIZAGEM BASEADA EM PROBLEMAS - ABP}

A Aprendizagem Baseada em Problemas ou ABP (também conhecida pela sigla PBL, iniciais do termo Problem Based Learning) é uma metodologia ativa que surgiu na Universidade de McMaster, no Canadá, em 1969. Berbel (2011) menciona que essa metodologia, inserida no conjunto das metodologias ativas, foi inicialmente introduzida no Brasil em currículos de Medicina, e depois experimentada em outros cursos. Segundo Ribeiro (2005), constituise em uma estratégia de ensino e aprendizagem que objetiva desenvolver o raciocínio, habilidades e atitudes. A busca na resolução do problema retira do professor o papel de protagonismo, transferindo-o para o aluno, que é incentivado a aprender com mais independência e de forma colaborativa com seus colegas.

Para Decker e Bouhuijs (2009), a metodologia ABP conduz o aprendizado por meio da reflexão, diálogo e da troca de experiências, entre professor e aluno, em que ambos compartilham o processo de construção do conhecimento, para serem desenvolvidos em situações reais das organizações.

Martins e Frezatti (2015), destacam que a ABP é a ponte que liga o ensino e a prática empresarial buscando a formação de profissionais preocupados em solucionar problemas de exemplos reais das empresas, reduzindo assim a distância da teoria e da prática no âmbito acadêmico.

Para Gil (2015), a aprendizagem baseada em problemas e os princípios do construtivismo estão centrados no aluno, baseiam-se no trabalho com pequenos grupos, os professores como facilitadores e enfatizam a formulação de problemas para desenvolver habilidades e para a obtenção de novas informações.

A aprendizagem baseada em problemas inicia com a apresentação de um problema, seguido da discussão em classe, com pesquisa colaborativa e auxílio do professor estimulando a reflexão.

Ribeiro (2008, p. 30) diz que "o problema deve ser suficientemente aberto para que ao aluno possa contribuir com algo para sua solução, não somente a aplicação ou cópia de material encontrado em livros". O professor precisa 
propor problemas cotidianos e vivenciados nas empresas para os futuros profissionais, no intuito de poderem ter a noção da realidade do dia a dia das organizações.

Para Gil (2015), a ABP dá mais ênfase na compreensão do assunto abordado do que na memorização, favorece a transferência dos conhecimentos, maior responsabilidade pela própria aprendizagem por parte dos alunos, aprimoramento do espírito de grupo, aprendizado com maior prazo de validade no que se refere a pensar, pesquisar e comunicar-se e trabalho em equipe.

O Quadro 1 apresenta de forma sucinta o papel do aluno e professor no ensino convencional e na ABP.

Quadro 1 - O papel do aluno e professor no ensino convencional e na ABP

\begin{tabular}{|c|c|}
\hline Ensino convencional & Metodologia ABP \\
\hline Professor & Professor \\
\hline $\begin{array}{l}\text { - Função de especialista ou autoridade } \\
\text { formal; } \\
\text { - Trabalho isolado; } \\
\text { - Transmissor de informação aos alunos; } \\
\text { - Conteúdo organizado em aula } \\
\text { expositiva; } \\
\text { - Trabalho individual por disciplina. }\end{array}$ & $\begin{array}{l}\text { - Orientador, co-aprendiz ou consultor; } \\
\text { - Trabalho em equipe; } \\
\text { - Ensina ao aluno gerenciar sua } \\
\text { aprendizagem; } \\
\text { - Curso organizado em problemas reais; } \\
\text { - Estímulo ao trabalho interdisciplinar. }\end{array}$ \\
\hline Aluno & Aluno \\
\hline $\begin{array}{l}\text { - Receptores passivos da informação; } \\
\text { - Trabalho individual isolado; } \\
\text { - Transcrição, memorização e repetição; } \\
\text { - Aprendizagem individualista e } \\
\text { competitiva; } \\
\text { - Busca resposta certa para sair bem na } \\
\text { prova; } \\
\text { - Avaliação dentro de conteúdos } \\
\text { limitados; } \\
\text { - Avaliação somativa e só o professor } \\
\text { avalia; } \\
\text { - Aula baseada em transmissão da } \\
\text { informação. }\end{array}$ & $\begin{array}{l}\text { - Valorização do conhecimento prévio; } \\
\text { - Interação com colegas e professores; } \\
\text { - Função de buscar e construir o } \\
\text { conhecimento; } \\
\text { - Aprendizagem em ambiente } \\
\text { colaborativo; } \\
\text { - Busca questionar e equacionar } \\
\text { problemas; } \\
\text { - Análise e solução ampla de problemas; } \\
\text { - Aluno e o grupo avaliam contribuições; } \\
\text { - Trabalho em grupo para buscar } \\
\text { soluções; } \\
\text { - Conhecimento é aplicado em vários } \\
\text { contextos. }\end{array}$ \\
\hline
\end{tabular}

Fonte: Do autor, com base em Barbosa e Moura (2013, p.59).

Segundo Escrivão e Ribeiro (2009), outros benefícios da ABP que cabem destaque são: uma maior participação dos alunos em sala de aula; interação professor-aluno e aluno-aluno; diversidade de visões sobre os temas; 
aproximação da teoria com a prática, maior envolvimento e comprometimento com a disciplina.

Young Digital Planet (2016), aponta que há também desafios no uso da aprendizagem baseada em problemas. Destacamos alguns:

- É uma metodologia que leva mais tempo de preparação do que as metodologias tradicionais de ensino;

- O professor precisa estar bem preparado com a escolha dos problemas;

- Intenso monitoramento por parte do professor quanto a participação dos alunos nas tarefas e as pesquisas de fontes duvidosas disponíveis na Internet;

- Poderá haver dificuldades na avaliação dos trabalhos dos alunos, pois não há semelhança com o sistema atual de avaliação das escolas;

- Os alunos levam mais tempo para se familiarizarem com esse método, no que se refere ao ordenamento dos trabalhos;

- Funciona com alunos motivados, pois em grupos menos motivados a eficácia diminui consideravelmente.

Assim, a ABP está alicerçada na prerrogativa da construção do conhecimento em um ambiente colaborativo, ao invés de ocorrer simplesmente a transmissão, individualização, repetição e memorização das informações aos alunos.

\section{METODOLOGIA DA PESQUISA}

De acordo com a professora Beatriz Francisca Chemin, a metodologia indica o modo como se pretende trabalhar na investigação e exposição da pesquisa. Sobre a pesquisa, Gil (2006, p.17), destaca que pode ser definida "como o procedimento racional e sistemático que tem como objetivo proporcionar respostas aos problemas que são propostos."

Apresenta-se a seguir o Quadro 2, com a delimitação da metodologia utilizada neste trabalho, com o objetivo de expor os caminhos que foram percorridos, não só no levantamento dos dados do estudo, como também na forma de fazê-lo. Os dados pesquisados, segundo os métodos adotados e em articulação ao referencial teórico, pretendem dar explicações, com o intuito de responder aos objetivos propostos. 


\begin{tabular}{|l|l|l|}
\hline $\begin{array}{l}\text { Quanto ao } \\
\text { método }\end{array}$ & Aplicada & $\begin{array}{l}\text { Buscou-se gerar conhecimento para desenvolver a } \\
\text { prática dirigida à solução de problema específico, em } \\
\text { uma turma de alunos. }\end{array}$ \\
\hline $\begin{array}{l}\text { Quanto à } \\
\text { forma de } \\
\text { abordagem }\end{array}$ & $\begin{array}{l}\text { Quanti- } \\
\text { qualitativa }\end{array}$ & $\begin{array}{l}\text { Preocupou-se com aspectos da realidade num } \\
\text { delineamento integrado de dados qualitativos } \\
\text { e quantitativos centrando-se na compreensão e } \\
\text { explicação da ABP. }\end{array}$ \\
\hline $\begin{array}{l}\text { Quanto aos } \\
\text { objetivos }\end{array}$ & Descritiva & $\begin{array}{l}\text { A coleta de dados foi realizada por meio de pesquisa } \\
\text { documental, monitoramento, questionário aplicado } \\
\text { e observações, pois reside na vontade de conhecer a } \\
\text { metodologia ABP. }\end{array}$ \\
\hline $\begin{array}{l}\text { Quanto aos } \\
\text { procedimentos } \\
\text { técnicos }\end{array}$ & $\begin{array}{l}\text { Pesquisa } \\
\text { bibliográfica }\end{array}$ & $\begin{array}{l}\text { Parte obrigatória de uma pesquisa, pois é de } \\
\text { natureza teórica, sendo que por meio dela se adquire } \\
\text { o conhecimento sobre produções científicas já } \\
\text { existentes, portanto forneceu os subsídios necessários } \\
\text { para o trabalho. }\end{array}$ \\
\cline { 2 - 3 } & $\begin{array}{l}\text { Pesquisa de } \\
\text { levantamento } \\
\text { ou survey }\end{array}$ & $\begin{array}{l}\text { Utilizou-se um questionário com perguntas abertas e } \\
\text { fechadas como instrumento da coleta de dados, sendo } \\
\text { que por meio dele buscou-se à resposta aos objetivos } \\
\text { deste trabalho. }\end{array}$ \\
\hline
\end{tabular}

Fonte: Do autor, com base em Chemin (2015).

A disciplina contemplou 18 encontros, de quatro horas aula semanais, no segundo semestre de 2017, em uma turma de 19 alunos, na disciplina de Contabilidade, no curso Técnico em Administração, do Centro de Educação Profissional da Universidade do Vale do Taquari - Univates.

No primeiro dia de aula, o professor apresentou um Contrato Pedagógico pronto para a turma. Nesse contrato foi mencionado a construção de um trabalho de problematização, formado por grupos, sujeito a avaliação oral após cada apresentação. Todos os alunos assinaram dando ciência do conteúdo e objetivos propostos. Para Garcia (2005), o contrato pedagógico não trata apenas de regras a serem cumpridas em sala de aula, de regimentos sobre condutas, entretanto, abrange rotinas, objetivos, limites e propósitos da disciplina. Esse documento precisa ser ratificado e sancionado entre os participantes quanto à ação pedagógica.

Do décimo quarto até o décimo sexto encontro, o assunto fluxo de caixa foi trabalhado em sala de aula num intervalo de três encontros. $\mathrm{O}$ referido conteúdo envolve a previsão de entradas e saídas de recursos monetários de uma entidade, por um período, ou seja, é a visualização das receitas e despesas distribuídas pela linha do tempo futuro. Os alunos receberam um problema elaborado pelo professor de uma situação real no dia a dia das empresas. No Quadro 3 apresenta o problema sobre o assunto, proposto na disciplina de Contabilidade. 
"Como vocês puderam observar na planilha elaborada em aula uma necessidade de empréstimos para cobrir o saldo final do DEMONSTRATIVO DOS SALDOS".

Problema: A empresa não entende que precisa buscar dinheiro fora para cobrir o caixa, pois acha possível ter uma solução sem esta busca junto à terceiros e arcando com mais juros. Como resolver essa situação?

Como administradores, façam um plano de ação ao proprietário da empresa para tentar zerar a necessidade de empréstimo.

O que vocês fariam para ajudar a empresa nessa situação? Explicar o plano de ação e refazer o fluxo de caixa com o plano montado por vocês.

Fonte: Do autor (2017).

$\mathrm{O}$ assunto foi trabalhado em três aulas consecutivas. Na primeira, o professor formou as duplas a seu critério, ou seja, utilizou a chamada e dividiu a mesma em dois grupos. Como eram 19 pessoas na turma, o primeiro aluno do primeiro grupo formou dupla com o primeiro do segundo grupo. $O$ segundo do primeiro grupo formou dupla com o segundo do segundo grupo e assim sucessivamente, portanto formaram-se nove duplas e um trio.

Após o problema ser lido, e os termos desconhecidos esclarecidos, o grupo foi auxiliado na montagem inicial dos quadros pertinentes as entradas e saídas de recursos monetários. A fundamentação teórica do assunto proporcionou o desenvolvimento das etapas que orientaram o estudo e que estão elencadas no Quadro 4.

Quadro 4 - Etapas que orientaram o estudo sobre a ABP

\begin{tabular}{|c|c|c|}
\hline Etapas & O que foi feito & Como foi feito \\
\hline Etapa 1 & $\begin{array}{l}\text { - Formação dos grupos de } \\
\text { alunos; } \\
\text { - Leitura inicial do assunto; } \\
\text { - Esclarecimento de termos } \\
\text { desconhecidos. }\end{array}$ & $\begin{array}{l}\text { - Critério adotado pelo professor; } \\
\text { - Auxílio na elaboração de planilhas que } \\
\text { compõem receitas, despesas, prazos de } \\
\text { pagamento e recebimento; } \\
\text { - Uso de notebooks da instituição de } \\
\text { ensino; } \\
\text { - Uso do editor de planilha eletrônica do } \\
\text { Google. }\end{array}$ \\
\hline Etapa 2 & $\begin{array}{l}\text { - Leitura do problema; } \\
\text { - Apresentação das } \\
\text { planilhas preenchidas, já } \\
\text { contemplando as novas } \\
\text { informações. }\end{array}$ & $\begin{array}{l}\text { - Cada dupla de alunos recebeu } \\
\text { informações diferentes; } \\
\text { - O professor fazia a conferência dos } \\
\text { resultados; } \\
\text { - Observação do professor quanto ao } \\
\text { andamento dos trabalhos. }\end{array}$ \\
\hline
\end{tabular}




\begin{tabular}{|c|c|c|}
\hline Etapas & O que foi feito & Como foi feito \\
\hline Etapa 3 & $\begin{array}{l}\text { - Apresentação do relatório } \\
\text { do plano de ação das duplas; } \\
\text { - Formação em } 4 \text { grandes } \\
\text { grupos; } \\
\text { - Apresentação do relatório } \\
\text { do plano de ação dos grupos; } \\
\text { - Entrega do resumo das } \\
\text { respostas dos grupos } \\
\text { compartilhadas para o } \\
\text { professor, pelo Google Drive. }\end{array}$ & $\begin{array}{l}\text { - Formação das classes na sala em forma } \\
\text { de “U”; } \\
\text { - Leitura oral de cada dupla para a turma; } \\
\text { - Leitura oral de cada grupo para a } \\
\text { turma; } \\
\text { - Apontamentos feitos pelo professor ao } \\
\text { final das apresentações. }\end{array}$ \\
\hline Etapa 4 & $\begin{array}{l}\text { - Avaliação correspondente a } \\
4,0 \text { pontos na terceira nota da } \\
\text { disciplina. }\end{array}$ & $\begin{array}{l}\text { - Elaboração e preenchimento das } \\
\text { planilhas 1,5 pontos; } \\
\text { - Elaboração e apresentação das duplas } \\
\text { 1,5 pontos; } \\
\text { - Elaboração e apresentação dos grupos } 1 \\
\text { ponto. }\end{array}$ \\
\hline
\end{tabular}

Fonte: Do autor (2017).

Destaca-se a realização da observação e monitoramento da participação dos integrantes das duplas e grupos nos três encontros.

A opinião dos alunos foi coletada no décimo oitavo encontro, por meio de um questionário sendo respondido por todos integrantes da turma. Composto de 7 questões, sendo 6 delas fechadas e 1 aberta, onde buscou-se a percepção dos respondentes no aprendizado com a $\mathrm{ABP}$ e uma análise da sua aplicabilidade na disciplina de Contabilidade.

O questionário foi elaborado no Google Formulários e enviado aos alunos por e-mail. Os respondentes puderam expressar suas opiniões, críticas, sugestões sendo mantido o anonimato dos autores das respostas.

\section{ANÁliSE DOS RESULTADOS}

Nesta seção serão apresentados os resultados da aplicação do questionário aos alunos e também as percepções do professor e também autor deste trabalho quanto ao uso da ABP.

\subsection{Perspectiva dos alunos}

Os resultados das questões respondidas foram verificados e tabulados para analisar a visão discente sobre a eficiência e aplicabilidade da ABP. A grade de respostas foi formada pela ordem de concordo fortemente, concordo, indeciso, discordo e discordo fortemente. 
Gráfico 1 - Metodologia promove a associação entre a teoria, a prática e a realidade

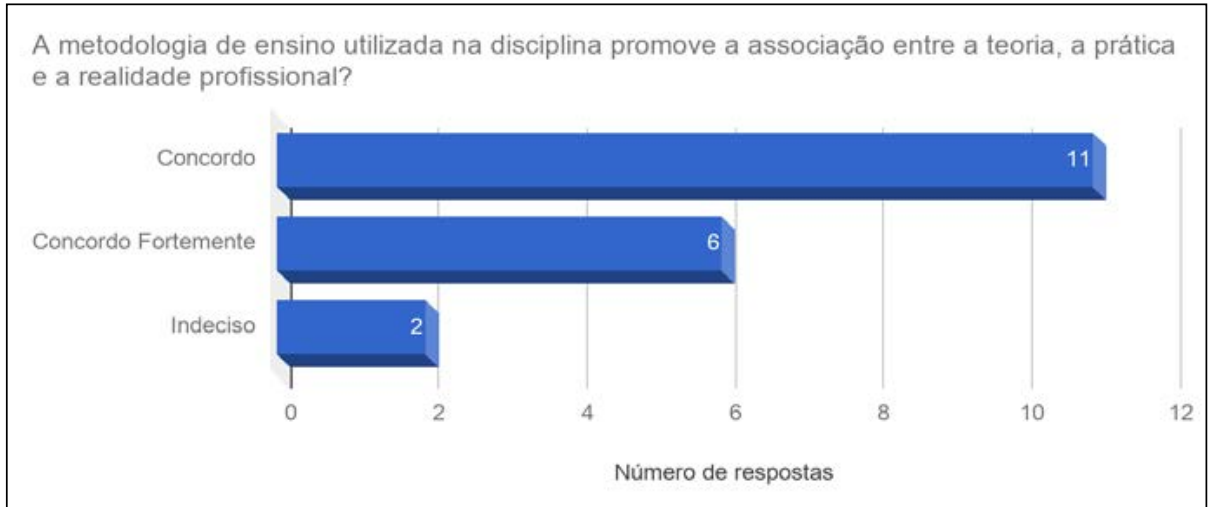

Fonte: Do autor (2017).

O objetivo da questão 1 foi analisar a percepção dos alunos quanto a abordagem da teoria, prática e a realidade no mercado profissional. No gráfico 1 pode-se observar que as respostas concordo fortemente e concordo representam $89 \%$, ou seja, 17 alunos percebem a associação entre a teoria, a prática e a realidade profissional com a metodologia aplicada.

Esse resultado vai de encontro ao que menciona Ribeiro (2008), quando diz que com base em conceitos, propostas, exemplos desenvolvidos da ABP, pode-se observar uma formação que permite integrar a teoria e prática, promovendo o domínio de conhecimentos específicos, habilidades e atitudes.

Gráfico 2 - Solução do fluxo de caixa na Aprendizagem Baseada em Problemas

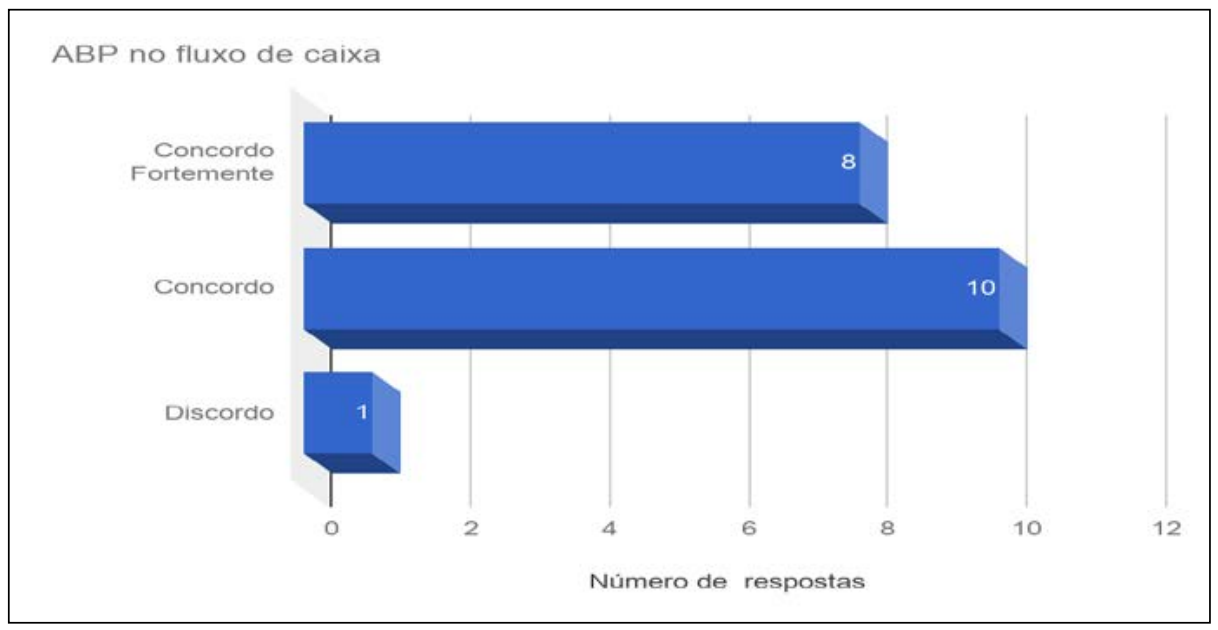

Fonte: Do autor (2017). 
A questão 2 traduz a essência do trabalho proposto dando início aos trabalhos da Aprendizagem Baseada em Problemas, desenvolvido em três encontros consecutivos, com ênfase no entendimento da problematização do fluxo de caixa e interação em grupo sobre a metodologia ABP.

O Gráfico 2 mostra que 10 alunos concordam, 8 responderam fortemente e 1 discordou. Em números relativos temos 95\%, o que isso indica que os respondentes se identificam como protagonistas visto o aprendizado ter sido centrado na solução do problema proposto por eles próprios de forma individual e coletiva.

O resultado corrobora com Ribeiro (2008) ao afirmar que um problema deve contemplar uma tarefa concreta, que possa trazer uma situação possível de ser resolvida e real aos futuros profissionais nas organizações.

Gráfico 3 - Análise de um problema em grupo

Análise de um problema sob diferentes pontos de vista na discussão do grupo

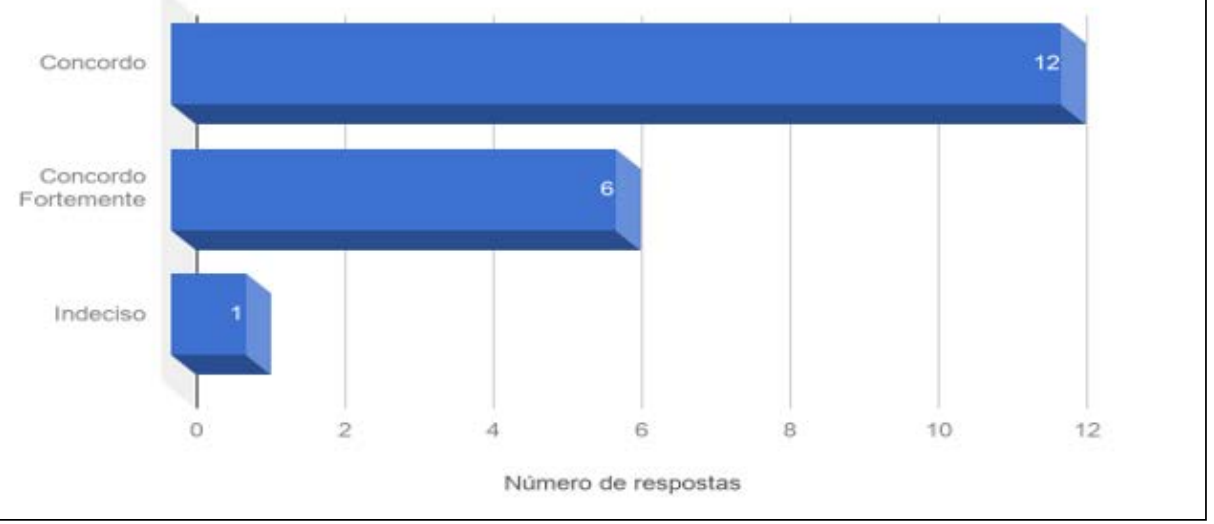

Fonte: Do autor (2017).

Ao analisar as respostas da questão 3, conforme Gráfico 3, sobre a ABP favorecer a discussão de um problema em grupo, observa-se que a grande maioria está de acordo. Dos que responderam à questão formulada, 12 alunos concordaram, 6 concordaram fortemente e 1 permaneceu indeciso.

Aos dados nos permitem inferir que a forma da condução da disciplina traduz a aceitação do trabalho em resolver um problema de forma coletiva, expondo ideias, apontamentos, discussões, intermediação do professor e consenso para chegar numa solução.

Para Anastasiou e Alves (2004), trabalhar em um grupo é diferente de fazer parte de um conjunto de pessoas, sendo imprescindível a interação, respeito ao coletivo, respeito à singularidade, do divergir, a habilidade em lidar com o outro, enfim, habilita o aluno no desempenho profissional, amparado na 
universidade como local que serve de ensaio para acertos e também de erros. No início alguns componentes mostraram-se um pouco tímidos, travados, mas aos poucos foram se soltando e desenvolvendo a tarefa com os demais colegas.

\section{Gráfico 4 - A interdisciplinaridade na ABP}

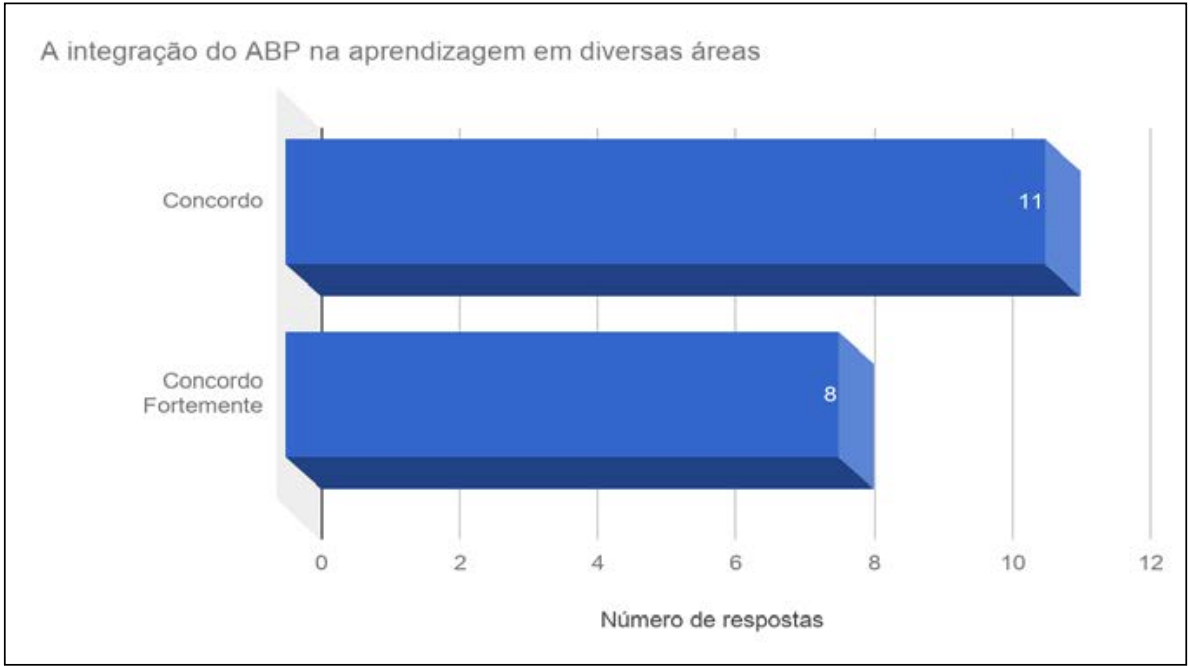

Fonte: Do autor (2017).

O Gráfico 4 demonstra que 8 alunos concordam fortemente e 11 concordam, representando $100 \%$, que a metodologia da resolução de problemas favorece a integração das aprendizagens de diversas áreas como contabilidade, vendas, marketing, engenharia de produção e outras. Mesmo não tendo o domínio total do assunto haverá uma visão geral para enfrentar situações comuns tratadas em outras disciplinas do curso.

Lück (2003, p. 64) diz que:

Interdisciplinaridade é o processo que envolve a integração e engajamento de educadores, num trabalho conjunto, de interação das disciplinas do currículo escolar entre si e com a realidade, de modo a superar a fragmentação do ensino, objetivando a formação integral dos alunos, a fim de que possam exercer criticamente a cidadania, mediante uma visão global de mundo e serem capazes de enfrentar os problemas complexos, amplos e globais da realidade atual. 
Gráfico 5 - ABP e a outras metodologias de ensino

O conteúdo $\mathrm{ABP}$ em relação a outras metodologias de ensino

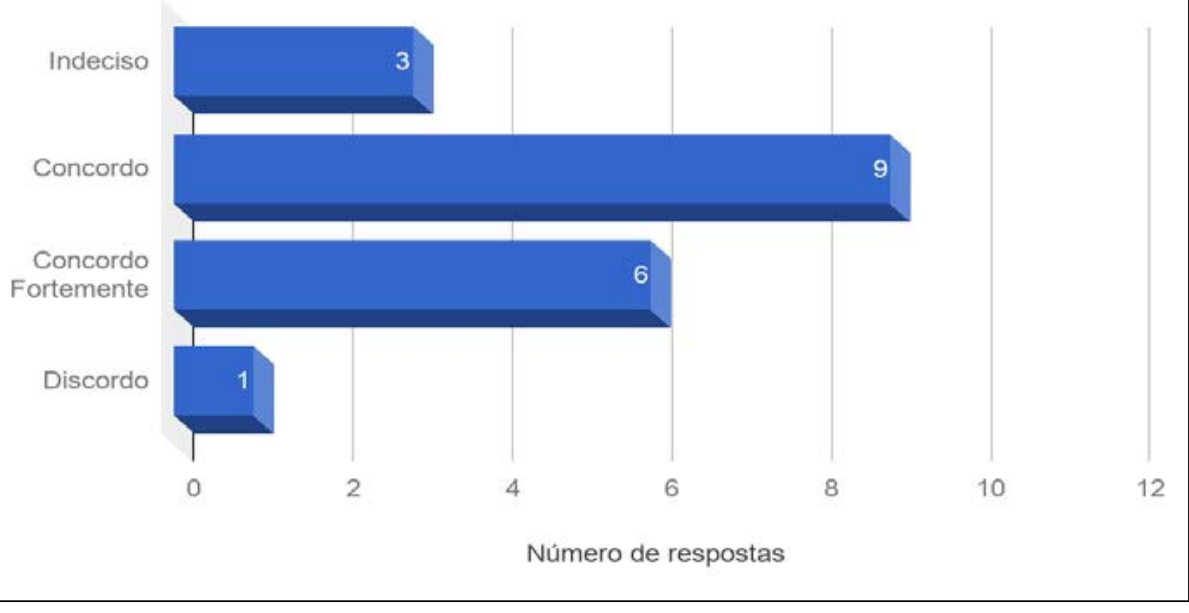

Fonte: Do autor (2017).

Observa-se que as respostas da questão 5 sobre o aprofundamento maior do conteúdo em relação às outras metodologias não estão concentradas em concordam, concordam fortemente, com a intensidade apresentada nas respostas anteriores. Os indecisos aparecem com 15\%, concordam com $47 \%$ e concordam fortemente apurou-se com $32 \%$.

Pode-se observar que 3 respondentes se colocaram indiferentes quanto ao aprofundamento de conteúdo do método de aprendizagem $\mathrm{ABP}$ e apenas 1 discordou. A maioria percebeu um aprofundamento maior do assunto em relação às outras metodologias.

Para Gil (2015), na ABP os alunos trabalham com o objetivo de solucionar problemas por meio de estudos, trabalhos em grupos, enfim nos princípios do construtivismo. Salienta-se qualquer metodologia de ensino utilizada a busca do aprender é de responsabilidade do aluno. 
Gráfico 6 - Trabalho em grupo na ABP

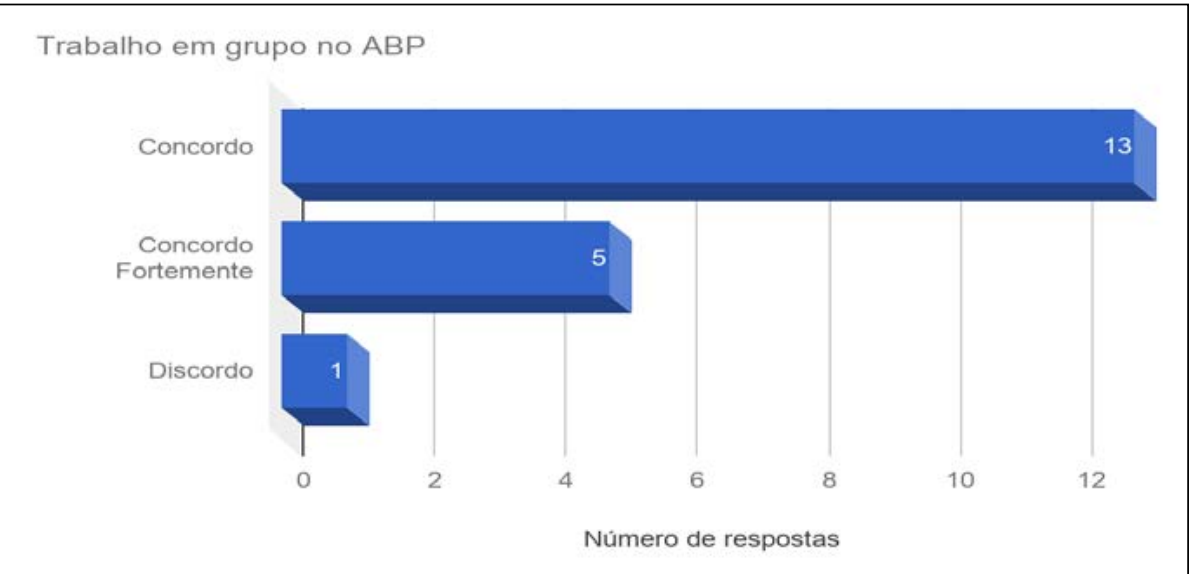

Fonte: Do autor (2017).

Em relação à motivação do trabalho em grupo na questão 6 apresentado no Gráfico 6, 68\% mostraram concordância, demonstrando que eles encontraram no problema proposto elementos motivadores na busca de uma solução. Dos outros, $26 \%$ tiveram forte concordância, com isso mostrando-se motivados no trabalho em grupo. $\mathrm{O}$ engajamento entre as partes será vital para a motivação e a iniciativa de aprender. ABP:

Segundo Gil (2015, p. 179), quando se refere à motivação trazida pela

A satisfação que os estudantes experimentam, consequentemente, tem muito mais a ver com a estratégia em si, do que com o carisma do professor ou com a qualidade dos recursos visuais. Assim, a ABP contribui para que os estudantes se automotivem.

Para Escrivão e Ribeiro (2009), o cerne dessa metodologia é o aluno sentir motivação de tomar a iniciativa para aprender, com a orientação e mediação do professor.

$\mathrm{Na}$ última questão, com comentários abertos, foi possibilitado que o aluno contribuísse com sugestões e críticas. Os relatos mais abrangentes e destacados nesta questão foram:

- A1: Gostei muito da metodologia utilizada por meio de resolução de problemas. dos alunos.

- A2: O método de ensino foi bom e o professor sempre foi prestativo nas dúvidas

- A3: A disciplina fez entender melhor a gestão de custos e o fluxo de caixa com a solução de problemas do dia a dia. O método de ensino foi bom e o professor sempre foi prestativo nas dúvidas dos alunos. 
- A4: Concordo que a metodologia de formar grupos para assim trabalhar seria para ambos se ajudarem, mas haviam colegas que não prestavam atenção, não participavam das tarefas do grupo.

As colocações dos respondentes na questão aberta evidenciam que a abordagem auferida nos três encontros sobre o assunto fluxo de caixa desenvolvidas por meio da $\mathrm{ABP}$ foram exitosas no quesito aprendizado. Contudo, há alguns aspectos merecedores de maior atenção e ajustes ao propor novamente a estratégia, pois obteve-se indícios da necessidade de contribuição mais ativa dos componentes dos grupos de forma a favorecer, a construção do conhecimento.

Ribeiro (2008), afirma que os alunos são sempre responsáveis pela aprendizagem, independentemente da metodologia de ensino adotada, assim ninguém poderá forçá-los a aprender, mas o empenho será um diferencial da aprendizagem.

\subsection{Perspectiva do professor}

A ABP é um método que estimula o pensamento crítico, habilidades para solução de problemas e a aprendizagem de conceitos na área em questão. A problematização foi abordada na elaboração do fluxo de caixa das empresas, pois trata-se de uma situação do mundo real, na qual geralmente traz complexidade na tomada de decisões dos administradores de empresas.

O Quadro 5 sintetiza os benefícios e dificuldades da metodologia na disciplina de Contabilidade ao longo dos três encontros sobre a ABP na percepção do professor.

Quadro 5 - Benefícios e dificuldades da metodologia ABP

\begin{tabular}{|l|l|}
\hline Benefícios & Dificuldades \\
\hline - Aprendizagem dinâmica e agradável; & - Desconforto inicial na implantação da \\
- Problema real dentro das empresas; & metodologia por parte dos alunos; \\
- Múltiplas visões sobre um mesmo & - Falta de pesquisa bibliográfica para \\
tópico; & resolução dos problemas com tentativas \\
- Quebra de rotina em relação às aulas & superficiais de solução; \\
expositivas; & - Maior dedicação docente; \\
- Facilitador dentro da sala de aula; & - Baixo conhecimento em planilhas \\
- Disponibilização de recursos & eletrônicas na grande maioria da turma; \\
necessários por parte da instituição de & - Pouca adesão de todos componentes nas \\
ensino; & discussões do grupo; \\
- Discussão em grupos; & - Conformismo e a zona de conforto; \\
- Turma de alunos em número & - Pouca interdisciplinaridade do assunto \\
pequeno. & abordado com outras disciplinas do curso. \\
\hline
\end{tabular}

Fonte: Do autor (2017). 
Os dados da pesquisa, bem como a percepção do professor, demonstram que os alunos participantes acreditam que aprendem melhor quando participam de forma ativa e desafiadora com situações do mundo real. Com base no conhecimento vivenciado e experimentado dentro da sala de aula, servirá de ensaio para acertos e também erros.

\section{CONCLUSÃO}

O desafio da proposta da $\mathrm{ABP}$ é proporcionar ao aluno a migração de uma aula expositiva, centrada no professor como detentor do conhecimento para uma flexibilização do processo tornando o aluno corresponsável por sua aprendizagem. Além disso, o trabalho da ABP pressupõe tirar o aluno da zona de conforto, onde o professor deixa de ser o protagonista, tornando o ambiente mais dinâmico, atrativo, com incentivo à cooperação no ambiente de sala de aula.

Faz-se necessário a construção do conhecimento por meio da estimulação ou até mesmo a ampliação dos significados aprendidos buscando a formação de profissionais preocupados em solucionar problemas do dia a dia das empresas, reduzindo a distância da teoria e da prática no âmbito acadêmico (ANASTASIOU E ALVES, 2004; MARTINS E FREZATTI, 2015).

O propósito deste artigo foi atender ao objetivo central de verificar, na percepção do docente e do grupo discente, possíveis reflexos na aprendizagem baseada em problemas, conhecida pela sigla $A B P$, na disciplina de Contabilidade.

As respostas dos alunos por meio do questionário, demonstram que 95\% dos respondentes atribuem o aprendizado centrado na solução do problema por eles próprios fazendo o papel de protagonistas e em $100 \%$ das respostas apontam que a metodologia integra a aprendizagem em diversas áreas como contabilidade, vendas, marketing e outras. Mesmo não tendo o domínio total do assunto, todavia poderá ter situações comuns tratadas em outras disciplinas do curso.

Em relação à motivação do trabalho em grupo, 68\% das respostas encontraram no problema proposto elementos motivadores na busca de uma solução. No aprofundamento de conteúdo do método de aprendizagem $\mathrm{ABP}$, revelam que $79 \%$ acham que a $\mathrm{ABP}$ auxilia na resolução de problemas e obtenção de novas informações. Ainda, $89 \%$ percebem a associação entre a teoria, a prática e a realidade profissional com a metodologia aplicada.

Analisando os dados da pesquisa, pela maioria das respostas, é possível inferir que os alunos desenvolveram competências e habilidades necessárias para elaboração do trabalho. Percebeu-se na estratégia de ensino o favorecimento de um bom funcionamento na dinâmica em sala de aula, e ainda, êxito no relacionamento entre professor e alunos. 
O trabalho apresentou contribuições para melhorias do processo de ensino e aprendizagem na disciplina de Contabilidade no curso Técnico em Administração, possibilitando ao professor elaborar aulas utilizando a ABP em produção conjunta com outras metodologias ativas, instigando o aluno a pensar e favorecendo a retenção do conhecimento.

\section{REFERÊNCIAS}

ANASTASIOU, Lea. G. C; ALVES, Leonir P. (Orgs). Estratégias de ensinagem. In: Processos de ensinagem na Universidade. Pressupostos para estratégias de trabalho em aula. 3. ed. Joinville: Univille, 2004. p. 67-100.

BARBOSA, Eduardo Fernandes; MOURA, Dácio Guimarães de. Metodologias ativas de aprendizagem profissional e tecnológica, Boletim técnico do SENAC, Rio de Janeiro, v. 39, n 2, p. 48- 67, 2013. Disponível em: <http://www.bts.senac.br/index. $\mathrm{php} / \mathrm{bts} / \mathrm{article} / \mathrm{view} / 349>$. Acesso em: $20 \mathrm{fev} .2018$.

BERBEL, Neusi Aparecida Navas. As metodologias ativas e a promoção da autonomia de estudantes. Semina: Ciências Sociais e Humanas, Londrina, v. 32, n. 1, p. 25-40, jan./jun. 2011. Disponível em: http://www.proiac.uff.br/sites/default/ files/documentos/berbel_2011.pdf >. Acesso em: 10 jan. 2018.

CHEMIN, Beatriz Francisca. Manual da Univates para trabalhos Acadêmicos. 3. ed. Lajeado: Ed. da Univates, 2015.

DECKER, Isonir da Rosa; BOUHUIJS, Peter. (2009). Aprendizagem baseada em problemas e metodologia da problematização: identificando e analisando continuidades e descontinuidades nos processos de ensino aprendizagem. In: U. F. Araújo \& G. Sastre (Orgs.). Aprendizagem baseada em problemas no ensino superior. (pp. 177-2014). São Paulo: Summus.

ESCRIVÃO, Edmundo Filho; RIBEIRO, Luís Roberto de Camargo. Aprendendo com PBL: aprendizagem baseada em problemas: relato de uma experiência em cursos de engenharia da EESCUSP. Rev. Minerva, São Carlos, v. 6. n. 1, p. 23-30, jan/abr. 2009. Disponível em: <http://www.fipai.org.br/Minerva\%2006(01)\%2003.pdf>. Acesso em: 19 jan. 2018.

GARCIA, Cláudia. As possibilidades do contrato pedagógico em sala de aula: Estudo em uma escola da periferia de Porto Alegre. 2005. Disponível em: <http:// www.lume.ufrgs.br/handle/10183/17716>. Acesso em: 04 fev. 2018.

GIL, Antônio Carlos. Como elaborar Projetos de Pesquisas. 4. ed. São Paulo: Atlas, 2006.

GIL, Antônio Carlos. Didática do Ensino Superior. 9. Ed. São Paulo: Atlas, 2015.

LÜCK, Heloisa. Pedagogia Interdisciplinar: fundamentos teórico-metodológicos. 11. Ed. São Paulo: Vozes, 2003. 
MARTINS, Daiana Bragueto; FREZATTI, Fábio. Problem-Based Learning no Ensino em Contabilidade Gerencial: Experiência numa Instituição de Ensino Superior.2015 Disponível em: <http:/ / www.congressousp.fipecafi.org/anais/artigos2015/290>. Acesso em: 28 jan. 2018.

MORAN, José. Mudando a educação com metodologias ativas. 2013 Disponível em: <www.2.eca.usp.br/moran/wp-content/uploads/2013/12> Acesso em: 08 jan. 2018.

YOUNG DIGITAL PLANET. Educação no século XXI: Tendências, ferramentas e projetos para inspirar. São Paulo: Fundação Santillana, 2016. Disponível em: <http:// new.smartlab.me/baixegratis-nosso-livro-educacao-no-seculo-21>. Acesso em: 09 jan. 2018.

RIBEIRO, Luis Roberto de Camargo. A aprendizagem baseada em problemas (PBL): uma implementação na educação em engenharia. Tese (Doutorado) - UFSC, Florianópolis, 2005. Disponível em: <https:/ / repositorio.ufscar.br/bitstream/handle/ ufscar/2353> Acesso em: 08 fev. 2018.

RIBEIRO, Luis Roberto de Camargo. Aprendizagem baseada em problemas (PBL): uma experiência no ensino superior. São Carlos: EdUFSCar, 2008. 